\title{
PATOFISIOLOGI KESADARAN MENURUN
}

\author{
Akina Maulidhany Tahir* \\ *Bagian Anatomi Fakultas Kedokteran UMI
}

Kesadaran adalah kondisi sadar terhadap diri sendiri dan lingkungan. Kesadaran terdiri dari dua aspek yaitu bangun (wakefulness) dan ketanggapan (awareness). (Avner,2006) Kesadaran diatur oleh kedua hemisfer otak dan ascending reticular activating system (ARAS), yang meluas darimidponskehipotalamusanterior. RAS terdiri dari beberapa jaras saraf yang menghubungkan batang otak dengan korteks serebri. Batang otak terdiri dari medulla oblongata, pons, dan mesensefalon. Proyeksi neuronal berlanjut dari ARAS ke talamus, dimana mereka bersinaps dan diproyeksikan ke korteks. (Ganong,2016)

Ketidaksadaran adalah keadaan tidak sadar terhadap diri sendiri dan lingkungan dan dapat bersifat fisiologis (tidur) ataupun patologis (koma atau keadaan vegetatif). (Avner,2006) Penyebab kesadaran menurun beragam dengan karakteristik masingmasing. Banyak penyebab dari penurunan kesadaran merupakan ancaman jiwa yang membutuhkan intervensi yang cepat, karena berpotensi terhadap morbiditas dan mortalitas yang tinggi. Perubahan fisiologis yang terjadi pada pasien dengan gangguan kesadaran antara lain pada pemenuhan kebutuhan dasar yaitu gangguan pernafasan, kerusakan mobilitas fisik, gangguan hidrasi, gangguan aktifitas menelan, kemampuan berkomunikasi, gangguan eliminasi (Hudak \& Gallo, 2002).

\section{FISIOLOGI KESADARAN}

Formasi retikuler berperan penting dalam menentukan tingkat kesadaran. RAS adalah jalur polysynaptic kompleks yang berasal dari batang otak (formasi retikuler) dan hipotalamus dengan proyeksi ke intalaminar dan nukleus retikular thalamus yang akan memproyeksi kembali secara menyeluruh dan tidak spesifik pada area luas dari korteks termasuk frontal, parietal, temporal, dan oksipital (Gambar 1). Jaras kolateralkedalamnyatidakhanya daritraktus sensoris, tetapi juga dari traktus trigeminal, pendengaran, penglihatan, dan penciuman. (Ganong, 2016) Kelainan yang mengenai lintasan RAS tersebut berada diantara medulla, pons, mesencephalon menuju ke subthalamus, hipothalamus, thalamus dan akan menimbulkan penurunan derajat kesadaran. (Wijdicks, 2010) 


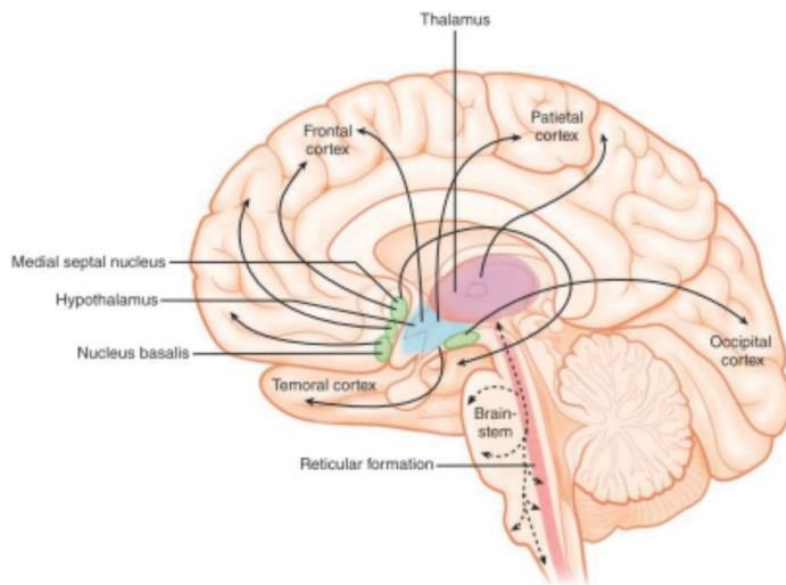

Gambar 1. Gambaran ascending reticular activating system (ARAS) pada batang otak (brainstem) memperlihatkan proyeksi pada thalamus dan korteks serebral (Ganong, 2016)

Kesadaran ditentukan oleh interaksi kontinu antara fungsi korteks serebri (kualitas) dengan Ascending Reticular Activating System (ARAS) (kuantitas) yang terletak mulai dari pertengahan bagian atas pons. ARAS menerima serabut-serabut saraf kolateraldarijaras-jaras sensoris dan melalui thalamic relay nuclei dipancarkan secara difus ke kedua korteks serebri. ARAS bertindak sebagai suatu tombol off-on, untuk menjaga korteks serebri tetap sadar (awake) (Wijdicks, 2010).

Respon gangguan kesadaran pada kelainan di ARAS ini merupakan kelainan yang berpengaruh kepada sistem arousal yaitu respon primitif yang merupakan manifestasi rangkaian inti-inti di batang otak dan serabutserabut saraf pada susunan saraf. Korteks serebri merupakan bagian yang terbesar dari susunan saraf pusat di mana kedua korteksini berperan dalamkesadaran akan diriterhadap lingkungan atau input-input rangsangan sensoris (awareness). Neurotransmiter yang berperan pada ARAS antara lain neurotransmiter kolinergik, monoaminergik dan Gamma Aminobutyric Acid (GABA). (Yeo, 2013)

\section{ETIOLOGI KESADARAN MENURUN}

Koma dapat disebabkan oleh penyakit yang menyerang bagian otak secara fokal maupun seluruh otak secara difus. Penyebab koma secara umum diklasifikasikan dalam intrakranial dan ekstrakranial (tabel 1). Selain itu, Koma juga dapat disebabkan oleh penyebab traumatik dan non-traumatik. Penyebab traumatik yang sering terjadi adalah kecelakaan lalu lintas, kekerasan fisik, dan jatuh. Penyebab non-traumatik yang dapat membuat seseorang jatuh dalam keadaan koma antara lain gangguan metabolik, intoksikasi obat, hipoksia global, iskemia global, stroke iskemik, perdarahan intraserebral, perdarahan subaraknoid, tumor otak, kondisi inflamasi, infeksi sistem saraf pusat seperti meningitis, ensefalitis dan abses serta gangguan psikogenik. (Greer, 2012)Keadaankomadapatberlanjutmenjadi kematian batangotakjikatidakadaperbaikan keadaan klinis. 
Tabel 1. Etiologi Penurunan Kesadaran (Howlett, 2012)

\begin{tabular}{|c|c|}
\hline $\begin{array}{l}\text { Site/aetiology } \\
\text { Intracranial }\end{array}$ & $\overline{\text { Disorder }}$ \\
\hline $\begin{array}{l}\text { Focal } \\
\text { stroke } \\
\text { infections } \\
\text { trauma } \\
\text { tumours }\end{array}$ & $\begin{array}{l}\text { infarct, ICH, SAH } \\
\text { brain abscess } \\
\text { haematoma (ICH, EDH, SDH) } \\
\text { primary or secondary }\end{array}$ \\
\hline $\begin{array}{l}\text { Diffuse } \\
\text { infections } \\
\text { seizures } \\
\text { trauma } \\
\end{array}$ & $\begin{array}{l}\text { HIV, meningitis, malaria, encephalitis } \\
\text { post ictal/status epilepticus } \\
\text { traumatic brain injury }\end{array}$ \\
\hline $\begin{array}{l}\text { Extracranial } \\
\text { hypoxia } \\
\text { metabolic/toxic } \\
\text { hypertension } \\
\end{array}$ & $\begin{array}{l}\text { cardiac, respiratory, renal, shock, anaemia } \\
\text { hyper-hypoglycaemia, organ failure, hyponatraemia overdose, opiates, alcohol } \\
\text { encephalopathy, eclampsia }\end{array}$ \\
\hline
\end{tabular}

Easy way to remember the causes of coma

$$
\begin{array}{ll}
\mathbf{A} & =\text { anoxia/apoplexy } \\
\mathbf{E} & =\text { epilepsy } \\
\mathbf{I} & =\text { injury/infection } \\
\mathbf{O} & =\text { opiates } \\
\mathbf{U} & =\text { uraemia }
\end{array}
$$

\section{PATOMEKANISME KESADARAN MENURUN}

Perilaku normal membutuhkan Pengetahuan dan Afek yang sesuai, sehingga seseorang mampu mengenali hubungan antara diri sendiri dan lingkungan. Komponen perilaku ini di kontrol oleh hemisfer otak. Pada umumnya, tubuh mengikuti ritmekesadaran yang normal. Dari kondisi kesadaran penuh (wakefulness) menjadi mengantuk, dan pada akhirnya tertidur. Pada satu titik selama tertidur (atau bahkan pada mengantuk), stimulus dari luar diproses melalui input sensoris untuk meningkatkan kondisi sadar dan menyebabkan seseorang menjadi sadar (bangun). Siklus ini dipicu secara predominan oleh ARAS, yang disebut sebagai pusat tidur. (Avner, 2006)
Pada penurunan kesadaran, gangguan terbagi menjadi dua, yakni gangguan derajat (kuantitas, arousal, wakefulness) kesadaran dan gangguan isi (kualitas, awareness, alertness) kesadaran. Adanya lesi yang dapat mengganggu interaksi ARAS dengan korteks serebri, apakah lesi supratentorial, subtentorial dan metabolik akan mengakibatkan menurunnya kesadaran (Taylor, 2006).

Pendekatan lain untuk menjelaskan level kesadaran adalah analogi "tombol onoff lampu". Perilaku (yang dikontrol oleh hemisfer otak) sebagai Bohlam Lampu dan Komponen kesadaran (dikontrol oleh ARAS) adalah tombol untuk menyalakan lampu. Untukmenyalakan lampu (kondisiseseorang menjadi Sadar), Lampu harus berfungsi dan menyala. Ada tiga kemungkinan Lampu tersebut tidak menyala (dalam hal ini 
Kesadaran Terganggu), yaitu adanya defek pada lampu itu sendiri (Disfungsi menyeluruh pada hemisfer otak), defek pada tombol lampu (abnormalistas dari ARAS), atau terdapat defek pada kedua lampu dan tombol lampu (DisfungsiCNSsecaraumum).(Avner,2006)

Model ini juga membantu membedakan penyebab dari penurunan kesadaran. ARAS di beberapa refleks batang otak, termasuk refleks cahaya pada pupil (nervus kranial II dan III) dan refleks pergerakan mata (nervus kranial III, VI, VIII, dan fasciculus longitudinal medial). Pemeriksaan pada refleks ini mengindikasikan fungsi dari ARAS. (Avner, 2006) Adanya trauma pada area ARAS dapat menyebabkan hilangnya refleks batang otak dan gangguan kesadaran, meskipunhemisfer otak tetap dalam kondisi normal. Disfungsi otak difus biasanya akibat riwayat penyakit medis seperti keracunan, gangguan metabolik dan infeksi menyebabkan penekanan (kompresi) pada ARAS yang merupakan akibat gangguan struktural(Tabel 2).

Tabel 2. Berbagai Penyakit Penyebab Penurunan Kesadaran (Avner, 2006)

\section{Gangguan Struktural}

Gangguan Medis (Toxic-Infeksi-Metabolik)

- Kejadian cerebrovascular
- Trombosis Vena Otak
- Hidrocefalus
- Tumor Intraserebral
- Empiema Subdural
pembengkakan otak secara difus, shaken baby
syndrome)

- Kejadian cerebrovascular

- Trombosis Vena Otak

- Hidrocefalus

- Tumor Intraserebral

- Empiema Subdural pembengkakan otak secara difus, shaken baby

\author{
- Anoxia \\ - Ketoasidosis Diabetes \\ - Abnormalitas elektrolit \\ - Encephalopathy \\ - Hipoglikemia \\ - Hipotermi / Hipertermi \\ - Infeksi (sepsis) \\ - Meningitis dan encephalitis \\ - Psikogenik \\ - Intususepsi \\ - Toksin \\ - Uremia (Sinfrom uremi-hemolitik)
}

Periode hilangnya kesadaran sesaat berarti hilangnya kesadaran intermiten dan muncul secara mendadak dari pasien yang sebelumnya telah sadar penuh. hal ini terdapat pasien dengan penyakit kardiovaskular dengan penurunan aliran darah ke otak secara akut (syncope) ataupun gangguan aktivitas elektrik pada otak (kejang). Lesi fokal otak yang terjadi di bawah tentorium (Gambar 2.A) akan mengganggu RAS sehingga dapat menyebabkan koma sedangkan lesi fokal terjadi di atas tentorium dalam satu hemisfer otak menyebabkan koma hanya jika sisi kontralateral otak secara bersamaan terlibat atau terkompresi (Gambar 2.B) Lesi menyebar (difus) otak, yang mempengaruhi fungsi otak secara keseluruhan termasuk RAS dapat menyebabkan koma (Gambar 2.C). (Howlett, 2012) 

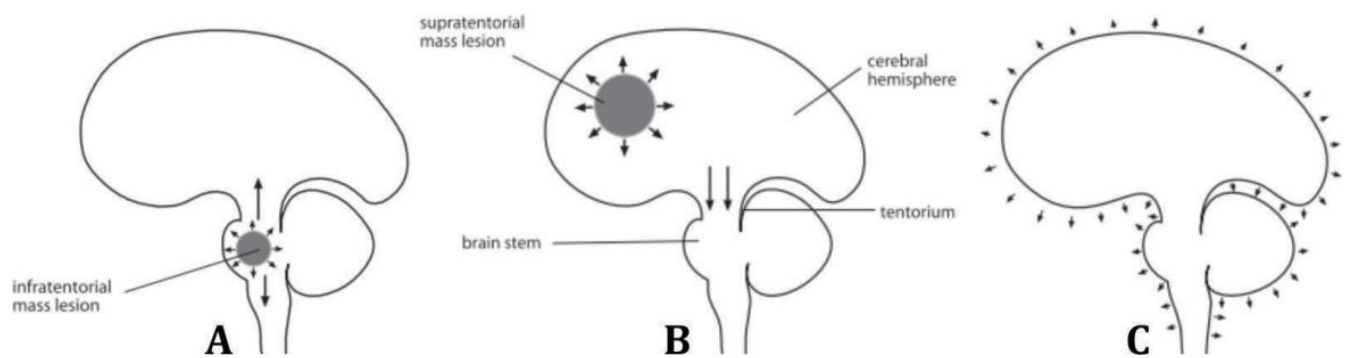

Gambar 2. Gambaran Lesi yang menyebabkan Penurunan Kesadaran. Gbr A \& B menunjukkan Lesi fokal. Gbr C. menunjukkan pada kondisi Encephalophaty Diffuse. (Howlet, 2012)

\section{PENILAIAN TINGKAT KESADARAN}

Penilaian kesadaran secara kuantitatif dapat menggunakan Tabel penilaian Glasgow Coma Scale (GCS) (Tabel 3) atau Four Score (Tabel 4) (Huff,2012 dan Laureys, 2011). Tingkat kesadaran secara kualitatif dapat dibagi menjadi kompos mentis, apatis, somnolen, stupor, dan koma. (Singhal, 2014)

- Kompos mentis berarti keadaan seseorang sadar penuh dan dapat menjawab pertanyaan tentang dirinya dan lingkungannya.

- Apatis berarti keadaan seseorang tidak peduli, acuh tak acuh dan segan berhubungan dengan orang lain dan lingkungannya.

- Somnolen berarti seseorang dalam keadaan mengantuk dan cenderung tertidur, masih dapat dibangunkan dengan rangsangan dan mampu memberikan jawaban secara verbal, namun mudah tertidurkembali.

- Sopor/stupor berarti kesadaran hilang, hanya berbaring dengan mata tertutup. Pasien dalam keadaan tiduryang dalam atau tidak memberikan respon dengan pergerakan spontan yang sedikit atau tidak ada dan hanya bisa dibangunkan dengan rangsangan kuat yang berulang (rangsang nyeri).
- Koma berarti kesadaran hilang, tidak memberikan reaksi walaupun dengan semua rangsangan (verbal, taktil, dan nyeri) dari luar. Pasien dalam keadaan tidaksadaryang dalam,yangtidak dapat dibangunkan akibat disfungsi ARAS di batang otak atau kedua hemisfer serebri. Karakteristik koma adalah tidak adanya arousal dan awareness terhadap diri sendiri dan lingkungannya.

Selain di atas terdapat juga tingkat kesadaran dalam bentuk lain, yaitu (Kumar, 2006)

- Kesadaran berkabut (clouding of consciousness) adalah penurunan keadaanbangun atau ketanggapanyang minimal, dimana masalah utamanya ialah perhatian atau kewaspadaan.

Confusion adalah gangguan dalam berpikir dengan jelas. Biasanya mempunyai gambaran gangguan kemampuan kognitif dan pengambilan keputusan.

Obstundasi yaitu penurunan kesadaran ringan-sedang dengan penurunan perhatian terhadap lingkungan dan reaksi terhadap rangsangyang lambat.

- Keadaan vegetatif diartikan sebagai kondisi tidak tanggap terhadap diri sendiri dan lingkungan yang disertai siklustidur-bangun(sleep-wakecycles) 
dengan fungsi autonomik hipotalamus dan batang otak yang lengkap atau parsial.

- Keadaan sadar minimal (minimally conscious state) adalah keadaan dimana kesadaran sangat terganggu, tetapi penderita dapat menunjukkan ketanggapan terhadap diri sendiri ataupun lingkungan secara intermitten.

Komayangterjadisecaratiba-tiba dapat memberi dugaan kejang atau perdarahan intrakranial. Koma yang didahului kantuk atau ketidakstabilan dapat memberi dugaan tertelannya obat-obatan atau racun. Demam biasa terjadi pada anak koma karena proses infeksi. Riwayat nyeri kepala dapat memberi dugaan adanya peningkatan tekanan intrakranial. (Avner, 2006)

Peningkatan tekanan intrakranial dapat menyebabkan herniasi yang dapat mengakibatkan kerusakan otak permanen atau kematian. Gejala peningkatan tekanan intrakranial antara lain nyeri kepala yang berat, muntah, gangguan penglihatan, dan perubahan tingkah laku atau derajat kesadaran. Tanda-tanda klinis peningkatan tekanan intrakranial adalah edema papil, kelumpuhan saraf otak, status mental abnormal dan postur tubuh tertentu. Trias

Cushing yaitu bradikardi, hipertensi dan pernafasan tidak teratur merupakan tanda herniasi yang mengancam. (Howlett, 2012)

Tabel 3. Glasgow Coma Scale (GCS)

\begin{tabular}{ll}
\hline \hline & Nilai \\
\hline Respons Membuka Mata & \\
Spontan & 4 \\
Terhadap perintah/pembicaraan & 3 \\
Terhadap rangsang nyeri & 2 \\
Tidak membuka mata & $\mathbf{1}$ \\
\hline
\end{tabular}

\section{Respons Motorik}

Sesuai perintah 6

Mengetahui lokalisasi nyeri 5

Reaksi menghindar 4

Reaksi fleksi-dekortikasi 3

Reaksi ekstensi-deserebrasi 2

Tidak berespons 1

\section{Respons Verbal}

Dapat berbicara dan memiliki orientasi 5

baik

Dapat berbicara, namun disorientasi 4

Berkata-kata tidak tepat dan tidakjelas 3

(nappropriate words)

Mengeluarkan suara tidak jelas $\quad 2$

(incomprehensive sounds)

Tidakbersuara

Tabel 4. Four Score

\section{Respons Mata}

Buka mata, bola mata bergerak, dan 4 berkedip sesuai instruksi

Buka mata, namun bola mata tidak 3 mengikuti arah gerakan jari

Mata tertutup, namun membuka saat $\quad 2$ terdengar suara keras

Matatertutup, namun membuka saatada 1 rangsangan nyeri

Mata tetap tertutup walaupun ada $\quad 0$

rangsangan nyeri

\section{Respons Motorik}

Ibu jari tangan naik, tangan

menggenggam dan peace sign sesuai

instruksi

Melokalisasi nyeri

Reaksi fleksi terhadap nyeri

Extensor posturing 1

Tidak ada respons terhadap nyeri atau 0 generalized myoclonus status epilepticus

\section{Refleks Batang Otak}

Terdapat refleks pupil dan kornea 4

Satu pupil lebar dan fixed 3

Tidak ada refleks pupil atau refleks $\quad 2$

kornea

Tidak ada refleks pupil dan refleks $\quad 1$

kornea

Tidak ada refleks pupil, kornea, dan $\quad 0$

batuk

4

3

2

1

0




\section{Pernapasan}

Tidakdiintubasidan pola pernapasan $\quad 4$ teratur

Tidak diintubasi dan pola pernapasan $\quad 3$

Cheyne-Stokes

Tidakdiintubasidan pola pernapasan $\quad 2$

tidak teratur

Bernapas di atas ventilator rate $\quad \mathbf{1}$

Bernapas setara ventilator rate atau 0 apnea

Herniasi otak menyebabkan kerusakan mekanik langsung dan juga iskemik dan perdarahan karena distorsi pembuluh darah. Terdapat beberapa sindroma herniasi yaitu herniasi uncal, herniasi sentral transtentorial (diensefalon dan otaktengah/pontine bagian atas), serta herniasi medular/pontine bagian bawah, dimana sindroma herniasi uncal dan sentral transtentorial merupakan keadaan yang reversibel. Sindroma-sindroma di atas, dan perubahannya dari satu ke yang lainnya menunjukkan progresifitas dari herniasi yang dapat diketahui secara klinis. Pemeriksaan refleks batang otak sangat penting untuk mengetahui progresifitas tersebut. (Kumar, 2006)

\section{PENUTUP}

Kesadaran dipertahankan oleh sistem aktivasi retikuler (RAS) yang utuh di batang otak dan otak terhubung ke thalamus dan hemisfer otak. Sistem pengaktif retikuler (RAS) membuat seseorang tetap terjaga dan waspada selama periode bangun. Gangguan yang secara fisik mempengaruhi area ini dapat menyebabkan gangguan kesadaran dan kondisi kesadaran yang berubah. Patofisiologi yang mendasari penurunan kesadaran berdasarkan pada gangguan struktural dan medis dari tingkat gangguan kesadaran yang berubah. Pentingnya pemahaman mengenai mekanisme dan penyebab dari berbagai gangguan kesadaran sehingga mampu mengenali dan membedakan penyebab dasar pasien dengan kondisi kesadaran menurun.

\section{DAFTAR PUSTAKA}

1. Avner JR. (2006) Altered states of consciousness. Pediatricsin Review; 27: 331-8

2. Ganong W.F (2016). Review of Medical Physiology, 25nd ed. Mc Graw-Hill, Boston.

3. Greer DM, Yang J, Scripko PD, Sims JR, Cash S, Kilbride R, et al. (2012) Clinical examination for outcome prediction in nontraumatic coma. Crit Care Med.; 40: 1150-6. doi: 10.1097/ CCM.obo13e318237bafb.

4. Huff JS, Stevens RD, Weingart SD, Smith WS. (2012) Emergency neurological life support: Approach to the patient with coma. Neurocritical Care; 17(S1): 54-9.

5. Kumar,P. \& Clark,M. (2006) Clinical Medicine, 6th ed. Elsevier Saunders, Edinburgh London

6. Laureys S. (2011) How to examine a comatose patient. XX th World Congress of Neurology: WCN Teaching Course.

7. Singhal NS, Josephson SA. (2014) A practical approach to neurologic evaluation in the intensive care unit. J Crit Care; 29(4): 627-33.

8. Taylor DA, Ashwal S. (2006) Impairment of consciousness and coma. Dalam: Swaiman KE, Ashwal S, penyunting. Pediatric neurology, principles \& practice. Edisi ke-4. Philadelphia: Mosby;. h.1378-1400. 
9. Wijdicks EF, Varelas PN, Gronseth GS, Greer DM, (2010) American Academy of N. Evidence-based guideline update: Determining brain death in adults: Report of the quality standards subcommittee of the American Academy of Neurology. Neurology; 74:1911-8.)

10. Yeo SS, Chang PH, Jang SH. (2013) The ascending reticular activating system from pontine reticular formation to the thalamus in the human brain. Frontiers in Human Neuroscience [Internet]. [cited 2018 August 25];7. Available from: http://journal.frontiersin.org/ article/10.3389/fnhum.2013.00416/ abstract 
